Virginia Commonwealth University VCU Scholars Compass

2017

\title{
Aerobic fitness impacts sympathoadrenal axis responses to concurrent challenges
}

Heather E. Webb

Texas A\&M University Corpus Christi

Deena A. Rosalky

University of New South Wales

Matthew J. McAllister

Mississippi State University

Edmund O. Acevedo

Virginia Commonwealth University

Gary H. Kamimori

Walter Reed Army Institute of Research

Follow this and additional works at: http://scholarscompass.vcu.edu/phis_pubs

Part of the Medicine and Health Sciences Commons

(C) Springer-Verlag Berlin Heidelberg 2017

\section{Downloaded from}

http://scholarscompass.vcu.edu/phis_pubs/53

This Article is brought to you for free and open access by the Dept. of Physiology and Biophysics at VCU Scholars Compass. It has been accepted for inclusion in Physiology and Biophysics Publications by an authorized administrator of VCU Scholars Compass. For more information, please contact libcompass@vcu.edu. 


\title{
Aerobic fitness impacts sympathoadrenal axis responses to concurrent challenges
}

\author{
Heather E. Webb ${ }^{1} \cdot$ Deena A. Rosalky ${ }^{2} \cdot$ Matthew J. McAllister $^{3}$. \\ Edmund O. Acevedo ${ }^{4}$ Gary H. Kamimori ${ }^{5}$
}

Received: 24 June 2016 / Accepted: 19 December 2016 / Published online: 4 January 2017

(C) Springer-Verlag Berlin Heidelberg 2017

\begin{abstract}
The combination of mental and physical challenges can elicit exacerbated cardiorespiratory (CR) and catecholamine responses above that of a single challenge alone.

Purpose This study examined the effects of a combination of acute mental challenges and physical stress on cardiorespiratory and catecholamine responses.

Method Eight below-average fitness $\left(\mathrm{LF} V \mathrm{O}_{2 \max }=36.5\right.$ $\left.8 \pm 3.36 \mathrm{ml}^{-1} \mathrm{~kg}^{-1} \mathrm{~min}^{-1}\right)$ and eight above-average fitness $\left(\mathrm{HF} V \mathrm{O}_{2 \max }=51.18 \pm 2.09 \mathrm{ml}^{-1} \mathrm{~kg}^{-1} \mathrm{~min}^{-1}\right.$ ) participants completed an exercise-alone condition (EAC) session consisting of moderate-intensity cycling at $60 \%$ $V \mathrm{O}_{2 \max }$ for $37 \mathrm{~min}$, and a dual-challenge condition (DCC) that included concurrent participation in mental challenges while cycling.

Result The DCC resulted in increases in perceived workload, CR, epinephrine, and norepinephrine responses overall. HF participants had greater absolute CR and catecholamine responses compared to LF participants and quicker HR recovery after the dual challenge.

Conclusion These findings demonstrate that cardiorespiratory fitness does impact the effect of concurrent stressors on $\mathrm{CR}$ and catecholamine responses.
\end{abstract}

Communicated by Keith Phillip George.

Heather E. Webb

heather.webb@tamucc.edu

1 Department of Kinesiology, Texas A\&M University Corpus Christi, 358 Island Hall, Corpus Christi, TX 78412, USA

2 University of New South Wales, Sydney, Australia

3 Mississippi State University, Mississippi, MS, USA

4 Virginia Commonwealth University, Richmond, VA, USA

5 Walter Reed Army Institute of Research, Silver Spring, MD, USA
Keywords Dual stress $\cdot$ Cardiorespiratory fitness $\cdot$ SA axis $\cdot$ Epinephrine $\cdot$ Norepinephrine $\cdot$ Cardiovascular reactivity
Abbreviations
AUC Area-under-the-curve
CR Cardiorespiratory
EPI Epinephrine
DCC Dual-challenge condition
EAC Exercise-alone condition
HR Heart rate
HF Higher-fitness
LF Lower-fitness
NE Norepinephrine
SA Sympathoadrenal axis

\section{Introduction}

The human stress response involves hormonal responses from the hypothalamic-pituitary-adrenal (HPA) and sympathoadrenal (SA) axes, the former of which causes a release of cortisol and the latter which causes the release of catecholamines [epinephrine (EPI) and norepinephrine (NE)], and, in turn, increases in cardiorespiratory (CR) measures. Further, it has been demonstrated that when individuals are presented with a combination of mental and physical challenges, the result is exacerbation of cardiorespiratory (Acevedo et al. 2006; Szabo et al. 1994; Webb et al. 2008, 2010), catecholamine (Webb et al. 2008, 2011b), and cortisol (Webb et al. 2008, 2011b, 2013) responses compared to a single challenge alone.

There is evidence that aerobic fitness is associated with enhanced cardiovascular efficiency at rest as well as during submaximal exercise which is shown by lower absolute 
heart rate (HR) (Mastorakos et al. 2005; Sothmann et al. 1996). However, responses to mental stress may be associated with increased sensitivity (greater relative increases in HR responses). Previous literature reviews have failed to reach a consensus regarding the impact of CR fitness on CR reactivity to psychological stressors (Brotherhood et al. 1997; Claytor 1991; de Geus and van Doornen 1993; Jackson and Dishman 2006; Schuler and O'Brien 1997; Sothmann et al. 1996). The evaluative function of CR fitness is complicated by the use of absolute versus relative change in pertinent variables (i.e., absolute change in HR versus relative change from baseline) and further convoluted by the use of different measures of fitness (i.e., maximal oxygen consumption, percent of maximal oxygen consumption, lactate threshold, ventilatory threshold) by various research groups.

A limited number of research studies have demonstrated that higher fit individuals also respond with greater EPI and $\mathrm{NE}$ responses to cognitive challenges in combination with greater CR responses, (de Geus and van Doornen 1993; de Geus et al. 1993; Sothmann et al. 1991). However, each of these studies only investigated the physiological responses to a mental challenge alone. Acevedo et al. (2006) did examine relative and absolute HR differences between lower- and higher-fitness level individuals during a combined mental and physical stressor, with the HR responses observed (relative increase in HR, while absolute HR was similar) serving to suggest that the mechanisms responsible for these responses to a dual challenge may vary from those responsible for the adaptations in response to a single stressor (mental challenge). This conclusion is similar to Dayas et al. (2001) in their findings from animal models. However, no previous investigation has measured both CR and catecholamine responses to a dual-stress condition in reference to aerobic fitness levels.

This is of importance when considering that many individuals are subjected to a combination of stressors on a regular basis (i.e., first responders, military personnel, etc.). When psychological and physical stressors are considered independently, the inability to adapt and maintain allostatic balance among the SA and HPA axes has been linked to hypertension, atherosclerosis, endothelial dysfunction, obesity, depression, and immunosuppression (Nicolaides et al. 2015). Previous research has demonstrated an even greater exacerbation of these responses in dual-stress situations (Acevedo et al. 2006; Szabo et al. 1994; Webb et al. $2008,2010,2011 \mathrm{~b}, 2013)$. Ultimately, it is likely that exacerbated adaptations to stress can lead to cardiovascular disease, immune system suppression, and increased endothelial injury leading to plaque formation and the formation of thrombosis.

Therefore the purpose of this study was to examine $\mathrm{CR}$ and catecholamine (EPI and NE) responses between lower-fitness (LF) and higher-fitness (HF) level individuals exercising at the same relative intensity while exposed to a mental challenge. It was hypothesized that LF individuals would have a less metabolically efficient response to the dual-challenge situation, with resultant increases in $\mathrm{CR}$ responses and catecholamine levels above that of HF participants.

\section{Methods}

Sixteen apparently healthy males were recruited for participation in this study from the University community. A minimum of 8 pairs of participants (16 total) were determined to be needed for this experiment based upon standard deviation calculations of NE and EPI means at the conclusion of the combined mental and physical stress protocol from the results of a previous study (Webb et al. 2011b). To calculate the number of subjects needed, a 0.05 level of significance was utilized with a power of 0.80 for a repeated measures design.

The Human Research Ethics Council approved all procedures prior to the initiation of data collection. Participants were (a) classified as low-risk individuals as categorized by the American College of Sports Medicine (ACSM) risk stratification, (b) free of cardiorespiratory and metabolic disorders, (c) free of any known blood disorders (i.e., anemia, hemophilia), (d) without hearing or vision problems (including color-blindness), (e) free of a history of psychological disorders and/or chronic illnesses, (f) native English speakers, (g) not using any prescription or non-prescription medication or tobacco products, (h) consuming an average of less than ten alcoholic beverages per week, (i) not having experienced any significant life events within 30 days of participation (i.e., death in family, divorce, wedding), and (j) not having any significant coursework (papers, presentations, exams) within 3 days of session 2 or 3 .

Participants completed three testing sessions. During the initial session, participants granted written informed consent, completed a health history questionnaire, were familiarized with testing protocols and performed an assessment of maximal oxygen consumption $\left(V \mathrm{O}_{2 \max }\right)$. Sessions two and three consisted of either steady state exercise alone, or steady state exercise performed while completing a mental stress challenge. Session 2 was conducted within one week of the initial session, and a minimum of seven and maximum of 14 days separated sessions 2 and 3. The order of the sessions was randomized and counterbalanced within groups and between conditions. For sessions 2 and 3, participants reported to the laboratory at 0700 following an overnight $(8 \mathrm{~h})$ fast.

The $V \mathrm{O}_{2 \max }$ test assessment was performed on a CompuTrainer Pro Cycle ergometer with the workload beginning 
at $100 \mathrm{~W}$ and increasing by $50 \mathrm{~W}$ every $90 \mathrm{~s}$ until either the primary criterion of a plateau in oxygen consumption $\left(V \mathrm{O}_{2}\right)$ with an increase in workload was met or the two secondary criteria were achieved. The secondary criteria were (1) reaching age-predicted maximal heart rate and achieving a respiratory exchange ratio (RER) of greater than 1.1 (Howley et al. 1995). All metabolic measurements were performed utilizing a ParvoMedics TrueOne 2400 integrated measurement system. Air volume was measured continuously using a Hans Rudolf 3813 (Kansas City, MO) pneumotachometer to measure ventilation and prior to each experimental session the $\mathrm{O}_{2}$ and $\mathrm{CO}_{2}$ gas analyzers were calibrated with gasses of known composition.

Participants were classified as high-fitness (HF) or lowfitness (LF) level based upon the percentile values for maximal aerobic power (Pescatello 2013), with HF participants categorized in the 80th percentile or greater for their age $\left(V \mathrm{O}_{2 \max } \geq 51.1 \mathrm{ml}^{-1} \mathrm{~kg}^{-1} \mathrm{~min}\right)$ and LF participants in the 15th percentile or lower for their age $\left(V \mathrm{O}_{2 \max }\right.$ $\leq 36.7 \mathrm{ml}^{-1} \mathrm{~kg}^{-1} \mathrm{~min}$ ), which corresponds with "excellent" and "very poor" ratings for cardiorespiratory fitness. High-fitness participants were purposefully recruited from University sports clubs and teams (.i.e., triathlon, crew, cycling) and reported deliberate exercise an average of 6 days per week for a minimum of 90 min per day. LF participants in the study reported that they did not participate in a formal exercise program and that their lifestyle was largely sedentary in nature.

An intravenous catheter (Jelco, 20G, $25 \mathrm{~mm}$ ) was inserted into an antecubital vein in the non-dominant arm, and a needle-free extension set (Medex, SM5005) was connected to the catheter, which had a CLC2000 positive displacement connector (ICU Medical) attached to maintain patency of the catheter. All venous catheters were inserted prior to 0715 for both sessions and within a \pm 15 -min window to ensure consistency of testing time between sessions 2 and 3. Following a pre-exercise blood draw (0 min), participants were instructed to ride at a comfortable pedal cadence that could be maintained at for the entire session.

The dual-challenge (DCC) and exercise-alone (EAC) conditions consisted of moderate-intensity cycling at $60 \% V_{2 \max }$ for $37 \mathrm{~min}$. A workload of $60 \% \mathrm{VO}_{2 \max }$ was selected for this protocol because it was an intensity that would likely be below ventilatory and lactate threshold, and it has been used previously in similar protocols (Webb et al. 2008, 2010, 2011b). The workload was calculated using the equations developed by the ACSM (Pescatello 2013) and validated via cardiorespiratory measurement using a ParvoMedics TrueMax metabolic cart (ParvoMedics, Sandy, UT). Exercise was performed on a CompuTrainer Pro Cycle ergometer with workload controlled by a CompuTrainer Coaching Software (Version 1.1) program specifically written for each participant. An Authorware program

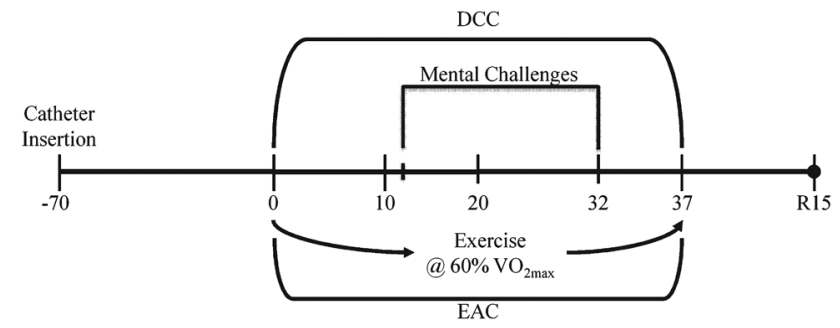

Fig. 1 Timeline of the experimental protocol in minutes. Serial blood draws (BD) were taken throughout the protocol via intravenous catheter at the time points specified. Participants cycled at $60 \% \mathrm{VO}_{2 \text { peak }}$ for a total of $37 \mathrm{~min}$ in both sessions. In the DCC condition, participants were also presented with a mental challenge from minute 12 until minute 32

(Macromedia 1999) was specifically written to maintain consistency in data collection timing for the experimental protocols.

The DCC also included participation in a mental challenge consisting of a modified computer-based Stroop Color Word (SCW) task and mental arithmetic (MA) task (Acevedo et al. 2006; Webb et al. 2008) while cycling from minute 12 until $32 \mathrm{~min}$. The mental challenge consisted of five cycles of the SCW and MA (2 min SCW plus 2 min MA) for a total of $20 \mathrm{~min}$ to promote psychological stress. These mental challenges are further described in the literature (Acevedo et al. 2006; Webb et al. 2008, 2013).

Additionally, during the mental challenges a research confederate provided critical, evaluative feedback to the participant to enhance the perceived stress. The confederate supplied commentary to the participant at systematic intervals suggesting that participant had answered incorrectly, was committing too many errors, or was taking too long to respond. At no time was positive feedback provided to the participant, nor was the feedback defamatory.

Cardiorespiratory measures of heart rate (HR), respiration rate $(\mathrm{RR})$, ventilation $\left(V_{\mathrm{E}}\right)$, ventilatory efficiency $\left(V_{\mathrm{E}} / V \mathrm{O}_{2}\right)$, oxygen consumption $\left(V \mathrm{O}_{2}\right)$, and respiratory exchange ratio (RER) were recorded during exercise (5, 10, 20, 32, and $37 \mathrm{~min}$ ) in both the DCC and EAC. Finally, within 5 min of completion of each condition, participants were asked to complete the NASA Task Load Index (NTLX) to assess the overall perceived workload (see Fig. 1).

The NTLX is a multi-dimensional subjective rating procedure that provides an overall workload score based on the ratings on six subscales: mental demands, physical demands, temporal demands, performance, effort, and frustration. Three of the NTLX dimensions are related to the demands imposed upon the subject (mental, physical, and temporal demands), while the remaining three dimensions are related to the interaction of a subject with the task (effort, frustration, and performance). Participants score 
each dimension on a $10 \mathrm{~cm}$ visual analog scale, ranging from "low" to "high" for mental, physical, temporal, effort, and frustration dimensions, and from "good" to "poor" on the performance dimension.

\section{Blood analysis}

Serial blood samples were collected for EPI and NE analyses at $0,10,20,32$, and 37 and R15 min. After each blood draw an equivalent volume of physiological saline was infused to equal the volume of blood withdrawn and maintain plasma volume. All blood draws were collected with the participant in an upright, seated position.

During each blood draw, the first $1 \mathrm{ml}$ of blood (with saline from the catheter lock) was collected into a discard tube preceding the sample draw and then $5 \mathrm{ml}$ was collected into tubes containing ethylene glycol-bes, $\beta$-aminoethyl ether- $N, N, N^{\prime}, N^{\prime}$-tetraacetic acid, and glutathione for catecholamine analysis. All blood samples were centrifuged immediately for $15 \mathrm{~min}$ at $2500 \mathrm{rpm}$ at $4{ }^{\circ} \mathrm{C}$, and the plasma samples were stored at $-80{ }^{\circ} \mathrm{C}$ for subsequent analyses. Hematocrit (microcapillary method) and hemoglobin values (Cyanmethemoglobin endpoint colorimetric method; Pointe Scientific, Canton, MI) were used to determine plasma volume shifts (Dill and Costill 1974).

Isolation of catecholamines from human plasma was accomplished by alumina extraction using a Chromosystems reagent kit (Munich, Germany). Once extracted, plasma catecholamine concentrations were quantified by high performance liquid chromatography (HPLC). The Waters (Waters Corp., Milford, MA) HPLC system consisted of a pump (model 510, WISP autoinjector (Model 712) with cooling module, column, and an electrochemical detector (Model 460). Data were stored and analyzed using the Waters Millennium software package (V 2.10). The flow rate was $0.8 \mathrm{ml}^{-1} \mathrm{~min}$, samples in the autoinjector were maintained at $4{ }^{\circ} \mathrm{C}$, and column oven was maintained at $40{ }^{\circ} \mathrm{C}$. The column was a $15 \mathrm{~cm}$ reversed phase $\mathrm{C}-18$ with $5 \mathrm{~m}$ silica particles. The sensitivity of the assay was 5 pg on a column with a signal to noise ratio of $4-1$, a between days coefficient of variation of less than $5 \%$, and a within days variation of less than $3 \%$. The standard curve for the range of $5-5000 \mathrm{pg}^{-1} \mathrm{ml}$ had a correlation coefficient of 0.998 .

\section{Statistical analysis}

All statistical procedures were conducted using SPSS version (22.0). Average wattage during exercise was analyzed utilizing paired $t$ tests, to compare workload in the two conditions. NTLX measures between the two conditions were also compared using paired $t$ tests to assess participants' perceptions of overall workload in each condition. Measures of $\mathrm{VO}_{2}$ and RER were examined using a $2 \times 5$ (condition $\times$ time) repeated measures analysis of variance (RMANOVA) to compare the physical stimulus in both conditions.

A $2 \times 2 \times 5$ (condition $\times$ fitness level $\times$ time $)$ RMANOVA was conducted on the CR variables (HR, $\mathrm{RR}, V_{\mathrm{E}}$, and $V_{\mathrm{E}} / V \mathrm{O}_{2}$ ) measures, with 1 min averages were calculated at $5,10,20,32$, and $37 \mathrm{~min}$ for analysis. To examine the CR changes from rest to exercise with mental challenge between the two groups, simple contrasts (independent $t$ tests) were conducted on the change scores from rest $(0 \mathrm{~min})$ to immediately pre-exercise $(10 \mathrm{~min})$ to the conclusion of the mental challenge $(32 \mathrm{~min}$ ) during exercise for $\mathrm{CR}$, if significant differences were found in the RMANOVA. Further, absolute CR differences at $32 \mathrm{~min}$ were also examined using a $t$ test, and CR changes from then end of the mental challenge ( $32 \mathrm{~min}$ ) to the conclusion of the exercise protocol (37 $\mathrm{min}$ ) were calculated and compared using simple contrasts.

Catecholamine (EPI and NE) values were analyzed using a $2 \times 2 \times 6$ (condition $\times$ fitness level $\times$ time) RMANOVA. Additionally, independent $t$ tests were conducted on the change scores in EPI and NE from rest to immediately pre-exercise to the conclusion of the mental challenge $(32 \mathrm{~min})$ during exercise. Further, differences in EPI and NE concentrations at 32 and 37 min were also examined using a $t$ test, and EPI and NE change scores from the end of the mental challenge ( $32 \mathrm{~min}$ ) until $15 \mathrm{~min}$ into the recovery period (R15 $\mathrm{min}$ ) were calculated and compared using simple contrasts.

To measure the overall release of EPI and NE during the two conditions and between fitness levels, integrated areaunder-the-curve (AUC) calculations for the two conditions were computed using a trapezoidal method following the subtraction of the average resting hormone concentration (at $0 \mathrm{~min}$ in both conditions) for each participant. Differences between AUC calculations of the two conditions were evaluated using $2 \times 2$ (fitness $\times$ condition) ANOVA. For all analyses, significant interactions were further evaluated utilizing one-way ANOVA and paired $t$ tests with Bonferroni corrections, with the $\alpha$-level set at $p \leq .05$.

\section{Results}

Eight HF individuals $\left(V \mathrm{O}_{2 \text { peak }}=51.18 \pm 2.09 \mathrm{ml} \mathrm{kg} \mathrm{\textrm {min } ^ { - 1 } )}\right.$ and eight $\mathrm{LF}$ individuals $\left(V \mathrm{O}_{\text {2peak }}=36.58 \pm 3.36 \mathrm{ml} \mathrm{kg} \mathrm{m}\right.$ in $^{-1}$ ) completed the initial familiarization session and two experimental sessions. One-way ANOVA revealed a significant difference between HF and LF participants for only $V O_{\text {2peak }}$ values $\left(F_{1,14}=108.77, p<.001\right)$. Physical characteristics of the participants can be found in Table 1 . 
Table 1 Means and standard deviations of participants' physical characteristics and cycling work and performance on mental challenge tasks (mean $\pm \mathrm{SD})$

\begin{tabular}{lrr}
\hline Variables & \multicolumn{2}{l}{ Mean $\pm \mathrm{SD}$} \\
\cline { 2 - 3 } & \multicolumn{1}{c}{$\mathrm{HF}(n=8)$} & $\mathrm{LF}(n=8)$ \\
\hline Age (years) & $22.13 \pm 4.85$ & $20.75 \pm 2.05$ \\
Height $(\mathrm{cm})$ & $174.00 \pm 5.95$ & $173.50 \pm 4.69$ \\
Weight $(\mathrm{kg})$ & $68.25 \pm 7.36$ & $70.48 \pm 8.82$ \\
Resting heart rate $(\mathrm{bpm})$ & $67.16 \pm 4.05$ & $66.19 \pm 7.75$ \\
$V \mathrm{O}_{2 \mathrm{max}}(\mathrm{ml} \mathrm{kg} \mathrm{min}$ & \\
Predicted $60 \% \mathrm{VO}_{2 \mathrm{max}}$ & $51.18 \pm 2.09^{\dagger}$ & $36.58 \pm 3.36$ \\
DCC actual $V \mathrm{O}_{2}\left(\mathrm{ml} \mathrm{kg}^{-1} \mathrm{~min}^{-1}\right)$ & $28.97 \pm 0.98^{\dagger}$ & $21.33 \pm 1.79$ \\
EAC actual $V \mathrm{O}_{2}\left(\mathrm{ml} \mathrm{kg}^{-1} \mathrm{~min}^{-1}\right)$ & $30.95 \pm 1.21^{\dagger}$ & $21.72 \pm 2.30$ \\
\hline
\end{tabular}

There was a significant difference between $\mathrm{HF}$ and $\mathrm{LF}$ for $V \mathrm{O}_{2 \max }$ and cycling workloads

$\dagger$ Significant fitness differences. Values for the DCC (dual challenge condition) and $\mathrm{EAC}$ (exercise-alone condition) actual $\mathrm{VO}_{2}$ measures are averages for the entire 37 min exercise protocol

\section{Comparison of workload between conditions}

A paired $t$ test revealed no significant difference for workload (average $\mathrm{W}$ ) between conditions or significant workload differences for HF or LF in their respective conditions, although HF participants did work at a significantly greater workload than LF participants in both the DCC $\left(F_{1,15}=43.37, p \leq .001\right)$ and the EAC $\left(F_{1,15}=44.09\right.$, $p \leq .001)$. Further, cycling cadence was not different between conditions for the HF or LF participants, respectively, and no differences were found between HF and LF participants in either condition. Additionally, no differences were seen between HF and LF participants on the mental challenges (see Table 2).

NTLX measures were assessed within $5 \mathrm{~min}$ of the conclusion of exercise to assess the perception of overall workload in each condition. NTLX scores were significantly higher in the DCC compared to the EAC $\left(71.5 \pm 5.2\right.$ and $46.9 \pm 4.9$, respectively; $t_{15}=6.64$, $p \leq .001)$ when all participants were considered. There was no significant difference in NTLX scores between HF and LF individuals, although both HF and LF did report significantly greater NTLX scores in the DCC $(\mathrm{HF}=71.5 \pm 5.2 ; \mathrm{LF}=76.0 \pm 5.3)$ when compared to the $\mathrm{EAC}(\mathrm{HF}=46.9 \pm 4.9 ; \mathrm{LF}=46.8 \pm 4.8)$.

RMANOVA analyses of RER values revealed only a main effect for time $\left(F_{4,176}=19.42, p \leq .001\right)$, with RER decreasing across time in both conditions and among both fitness groups. RMANOVA for $V \mathrm{O}_{2}$ revealed no significant interaction effects for condition by time by fitness, condition by fitness, or condition by time. A significant fitness $\mathrm{x}$ time interaction was observed $\left(F_{4,176}=2.86, p=.03\right)$,
Table 2 Cycling work and performance on mental challenge tasks (mean $\pm \mathrm{SD}$ )

\begin{tabular}{lcc}
\hline Variables & \multicolumn{2}{l}{ Mean $\pm \mathrm{SD}$} \\
\cline { 2 - 3 } & $\mathrm{HF}(n=8)$ & $\mathrm{LF}(n=8)$ \\
\hline Cycling work $(\mathrm{W})$ & $145.43 \pm 4.63^{\dagger}$ & $104.03 \pm 3.83$ \\
DCC & $145.50 \pm 5.01^{\dagger}$ & $104.25 \pm 3.68$ \\
EAC & & \\
Cycling cadence (rpm) & $69.5 \pm 9.3$ & $62.9 \pm 2.6$ \\
DCC & $69.8 \pm 9.2$ & $62.9 \pm 2.4$ \\
EAC & $93.5 \pm 1.6$ & $94.7 \pm 0.8$ \\
SCW $(\%$ correct $)$ & $87.0 \pm 2.8$ & $92.0 \pm 1.6$ \\
MA $(\%$ correct $)$ &
\end{tabular}

There was a significant difference between HF and LF workloads $\left(t_{14}=6.40, p=.001\right)$

$\dagger$ Significant fitness differences

as well as a main effect for time $\left(F_{4,176}=5.95, p \leq .001\right)$, with $\mathrm{VO}_{2}$ levels increasing across time and with HF participants having a greater $V \mathrm{O}_{2}$ level comparatively. There was, however, no significant difference in $\mathrm{VO}_{2}$ levels for $\mathrm{HF}$ or LF participants between conditions (see Fig. 2).

Additionally, calculations of $\mathrm{VO}_{2}$ values demonstrated that $\mathrm{HF}$ and $\mathrm{LF}$ participants' average $\mathrm{VO}_{2}$ values during exercise were not significantly different when compared to the predicted $60 \% V_{2} \mathrm{O}_{2 \text { peak }}$ values (see Table 1). These values demonstrate that HF participants exercised at approximately $58.5 \%$ of their $V_{2} \mathrm{O}_{2 \text { peak }}$ in the DCC and $60.5 \% \mathrm{VO}_{2 \text { peak }}$ in the EAC, while LF participants exercised at $58.4 \%$ of their $V \mathrm{O}_{2 \text { peak }}$ in the $\mathrm{DCC}$ and $59.5 \% \mathrm{VO}_{2 \text { peak }}$ in the EAC.

\section{Cardiorespiratory responses}

Analyses of HR responses revealed a significant condition by time by fitness interaction for $\operatorname{HR}\left(F_{4,176}=3.62, p=.015\right)$ with greater increases in the DCC compared to the EAC, and greater increases for HF individuals (see Figs. 3a, 4a). Posthoc analysis revealed significantly elevated HR in the DCC compared to the EAC at $20 \mathrm{~min}(\mathrm{DCC}=137.4 \pm 4.1 \mathrm{bpm}$; $\left.\mathrm{EAC}=124.9 \pm 2.6 \mathrm{bpm} ; t_{15}=5.40, p=.001\right)$ and $37 \mathrm{~min}$ $(\mathrm{DCC}=135.7 \pm 3.40 \mathrm{bpm} ; \mathrm{EAC}=129.1 \pm 2.72 \mathrm{bpm} ;$ $\left.t_{15}=4.42, p=.001\right)$. Post-hoc analysis of the DCC revealed elevations in $\mathrm{HR}$ in the $\mathrm{HF}$ compared to the $\mathrm{LF}$ at $5 \mathrm{~min}$ $\left(F_{1,15}=8.90, p=.001\right), 10 \min \left(F_{1,15}=7.94, p=.014\right)$, $20 \min \left(F_{1,15}=24.41, p=.001\right), 32 \min \left(F_{1,15}=31.62\right.$, $p=.001)$ and $37 \min \left(F_{1,15}=48.61, p=.001\right)$. See Table 3 for data.

Simple contrasts (independent $t$ tests) were conducted on change scores of the HF and LF groups for HR responses from rest $(-5 \mathrm{~min})$ to the end of the mental challenge 
(a)

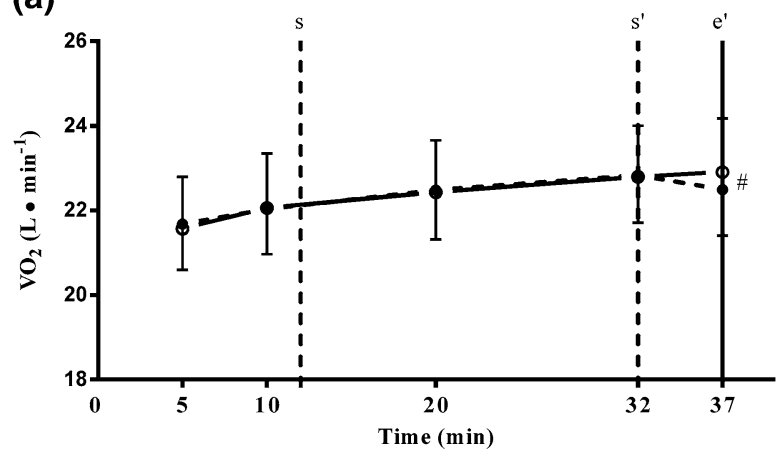

(c)

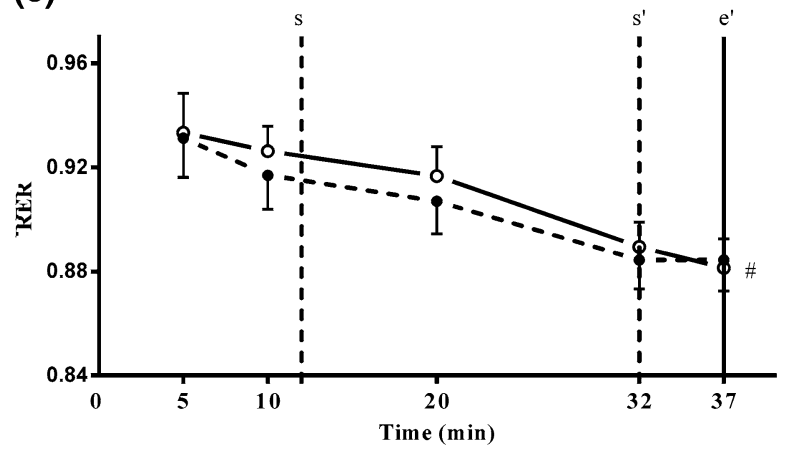

(b)

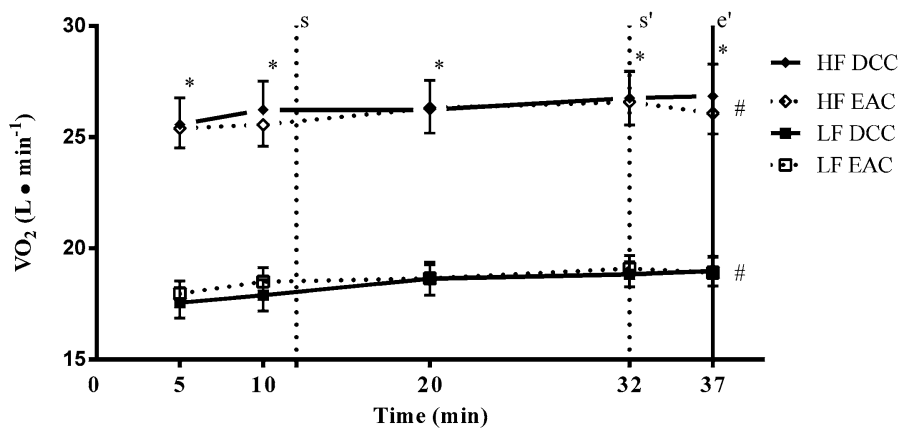

(d)

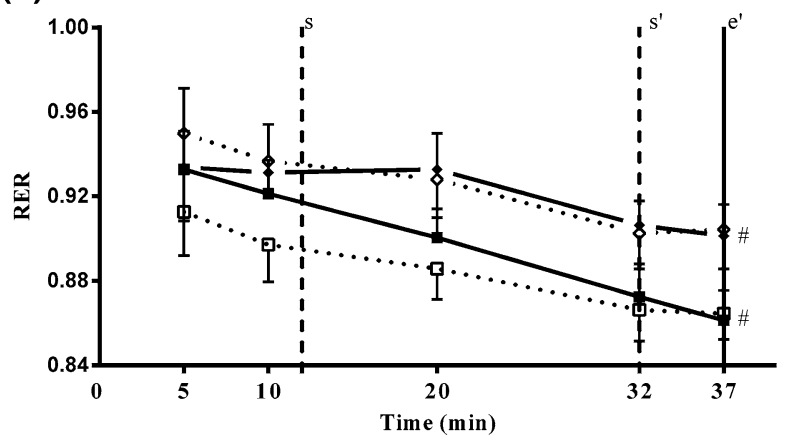

Fig. 2 Workload responses for $V \mathrm{O}_{2}$ (a) and RER (c) between the DCC and EAC conditions demonstrated significant changes across time ( ${ }^{\#} p<.05$ across time). High-fit participants (b) had significantly greater $V \mathrm{O}_{2}$ values compared to LF participants $\left({ }^{*} p<.05\right)$, while there were no differences between fitness groups for RER (d). Points represent the values at specific time points during the protocol; verti- cal lines depict standard errors of the means. The solid vertical lines extending from the ordinate represent the conclusion of the exercise $\left(e^{\prime}\right)$ component, while vertical dotted lines extending from the ordinate represent the start of the mental challenge $(s)$ and the end of the mental challenge $\left(s^{\prime}\right)$
(32 min). Relative HR change scores were significantly greater in the $\mathrm{HF}$ group $(\mathrm{LF}$ change $=61.9 \pm 8.6 \mathrm{bpm}$; $\mathrm{HF}$ change $\left.=84.3 \pm 7.5, t_{14}=5.62 \mathrm{bpm} ; p=.001\right)$. Absolute HR following $32 \mathrm{~min}$ of mental challenge was also significantly different between the two groups $(\mathrm{LF}=128.1 \pm 9.8 \mathrm{bpm}$ and $\mathrm{HF}=151.4 \pm 6.5 \mathrm{bpm})$. Further simple contrasts were conducted on change scores to compare post-mental challenge (change in HR from 32 to $37 \mathrm{~min}$ ) values. Absolute change scores for post-mental challenge HR was significantly different for HF participants $\left(t_{7}=3.41, p=0.01\right)$, although not for LF participants. Further, relative change scores for this time period were not significantly different for either HF or LF participants.

The RMANOVA for RR did not reveal a significant condition by time by fitness or a condition by fitness interaction effect. However, a significant condition by time $\left(F_{4,176}=6.82, p=.001\right)$ and fitness by time $\left(F_{4,176}=2.85\right.$, $p=.04)$ interaction effects were revealed, with greater increases in the DCC compared to the EAC and in the HF participants compared to the LF participants across time (see Figs. 3b, 4b). Post-hoc analysis revealed greater elevations in RR in the DCC compared to the EAC at $20 \mathrm{~min}$ $\left(t_{15}=3.51, p=.003\right)$ and $32 \min \left(t_{15}=2.40, p=.030\right)$. Additionally, HF participants had significantly greater changes in RR values across time compared to LF participants $\left(F_{4,176}=2.85, p=.04\right)$, although there were no time points in the DCC or EAC that were significantly different between the fitness levels.

The RMANOVA for $V_{\mathrm{E}}$ responses did not reveal significant condition by time by fitness interaction effects nor a significant fitness by time interaction, but RMANOVA did reveal a significant condition by fitness interaction $\left(F_{1,14}=5.11, p=.040\right)$ with greater increases in the DCC for $\mathrm{HF}$ participants (see Figs. 3c, 4c). Post-hoc analysis revealed greater $V_{\mathrm{E}}$ elevations among $\mathrm{HF}$ participants at $20 \min \left(t_{15}=2.88, p=.011\right)$ and $32 \min \left(t_{15}=2.56\right.$, $p=.022)$. In addition, significant main effects for condition $\left(F_{1,14}=5.28, p=.04\right)$ and time were also revealed $\left(F_{4,11}=9.69, p=.001\right)$.

The RMANOVA for $V_{\mathrm{E}} / \mathrm{VO}_{2}$ responses did not reveal significant condition by time by fitness, condition by fitness, or fitness by time interaction effects (see Figs. 3d, 4d), but did reveal a significant condition by time interaction $\left(F_{1,176}=9.71, p=.001\right)$, with greater elevations in the DCC 
(a)

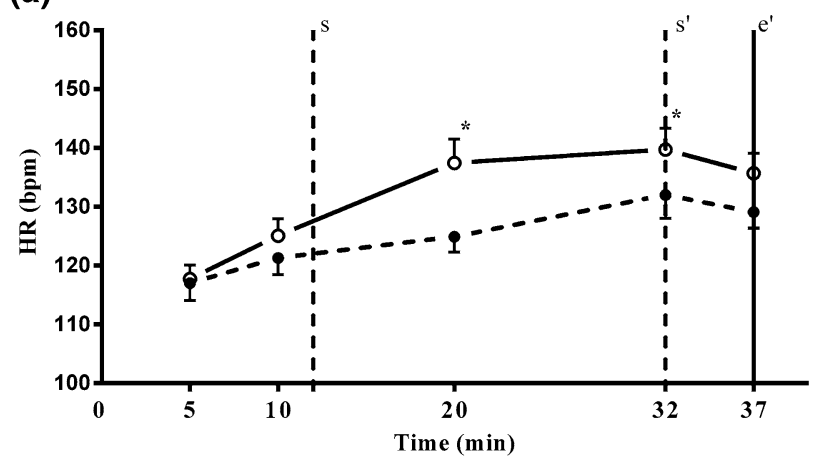

(b)

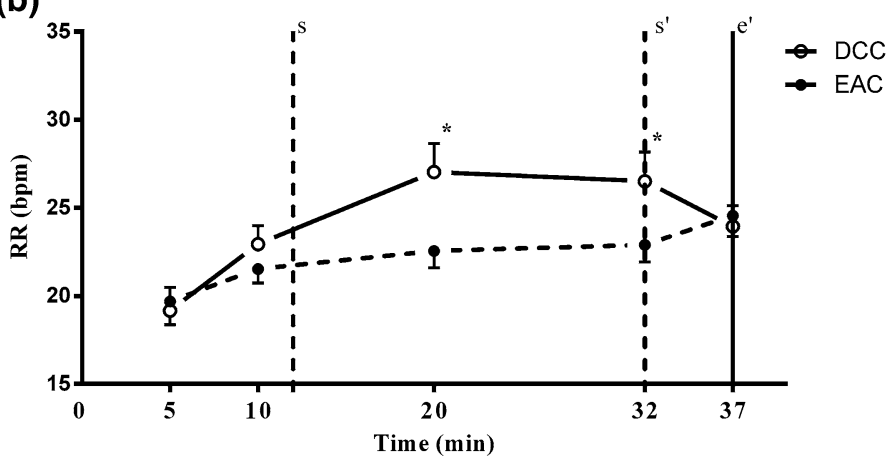

(c)

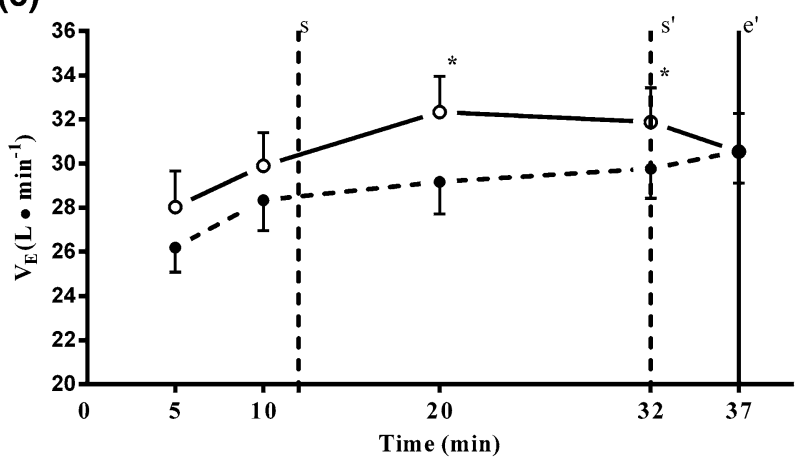

Fig. 3 Mean overall cardiorespiratory responses for a HR, b RR, c $V_{\mathrm{E}}$, and $\mathbf{d} V_{\mathrm{E}} / V \mathrm{O}_{2}$ for $\mathrm{HF}$ and LF participants combined in the DCC and EAC in the DCC and EAC. Significant differences were seen in each variable between conditions at 20 and $32 \min \left({ }^{*} p<.05\right.$ between conditions). Points represent the $\mathrm{CR}$ values at specific time points

compared to the EAC at $20 \min \left(\mathrm{DCC}=26.03 \pm .64 \mathrm{~L} \mathrm{~min}^{-1}\right.$; $\left.\mathrm{EAC}=24.30 \pm .73 \mathrm{~L} \mathrm{~min}^{-1} ; t_{15}=2.38, p=.031\right)$ and $32 \mathrm{~min}$ $\left(\mathrm{DCC}=25.19 \pm .59 \mathrm{~L} \mathrm{~min}^{-1} ; \mathrm{EAC}=23.65 \pm .44 \mathrm{~L} \mathrm{~min}^{-1}\right.$; $\left.t_{15}=2.73, p=.016\right)$. Significant main effects for condition $\left(F_{1,14}=20.84, p=.001\right)$ and time $\left(F_{4,11}=30.67, p=.001\right)$ were demonstrated.

\section{Catecholamine responses}

No differences in baseline $(0 \mathrm{~min})$ hormonal measures were observed for EPI (see Fig. 5a), or NE (see Fig. 5c). RMANOVA revealed a condition by time by fitness level interaction for EPI $\left(F_{5,55}=2.81, p=.045\right)$ with significant elevations across time among the HF group in the DCC (see Fig. 5c). Significant differences were revealed for condition by fitness level $\left(F_{1,11}=8.79, p<.05\right)$, time by fitness level $\left(F_{5,55}=6.49, p<.05\right)$, and condition by time $\left(F_{5,55}=5.18\right.$, $p<.05)$ interaction effects. Post-hoc analyses demonstrated that HF participants had significantly higher levels of EPI in the DCC at $32 \min \left(F_{1,15}=17.65, p<.05\right)$ and $37 \mathrm{~min}$ $\left(F_{1,15}=10.71, p<.05\right)$ than LF participants. Paired $t$ tests demonstrated that HF individuals had significantly greater (d)

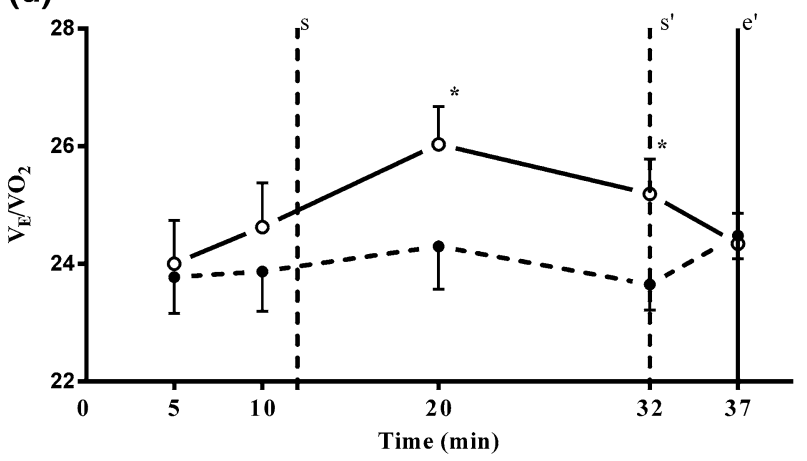

during the protocol; vertical lines depict standard errors of the means. The solid vertical lines extending from the ordinate represent the conclusion of the exercise $\left(e^{\prime}\right)$ component, while vertical dotted lines extending from the ordinate represent the start of the mental challenge $(s)$ and the end of the mental challenge $\left(s^{\prime}\right)$

levels of EPI at $32 \mathrm{~min}$ in the DCC $\left(t_{7}=3.17, p<.05\right)$. Furthermore, there was not a significant difference in the post-exercise measures of EPI.

There was not a significant condition by time by fitness level interaction for NE, but significant interaction effects were revealed for condition by fitness level $\left(F_{1,11}=16.66, p<.05\right)$ and time by fitness level $\left(F_{5,55}=5.33, p<.05\right)$. Post-hoc analyses revealed NE levels to be greater amongst HF participants, and that $\mathrm{NE}$ levels increased from 0 to $32 \mathrm{~min}$ and then decreased from 32 to R15 min. There was a significant difference in NE levels among HF participants at $32 \mathrm{~min}\left(t_{7}=3.04\right.$, $p<.05)$ and at $37 \mathrm{~min}\left(t_{7}=2.67, p<.05\right)$. LF participants demonstrated an increase in NE levels across time, with NE increasing from 0 to $37 \mathrm{~min}$, and then decreasing from 37 to R15 min as well. NE levels did not differ significantly at any time point between conditions for LF participant (see Fig. 5g). There was not a significant difference in the recovery measures of NE, although the recovery measures for HF participants approached levels of significance for NE, with NE levels decreasing to a greater extent post-exercise among HF participants than LF participants $\left(t_{14}=3.46, p=0.065\right)$. 

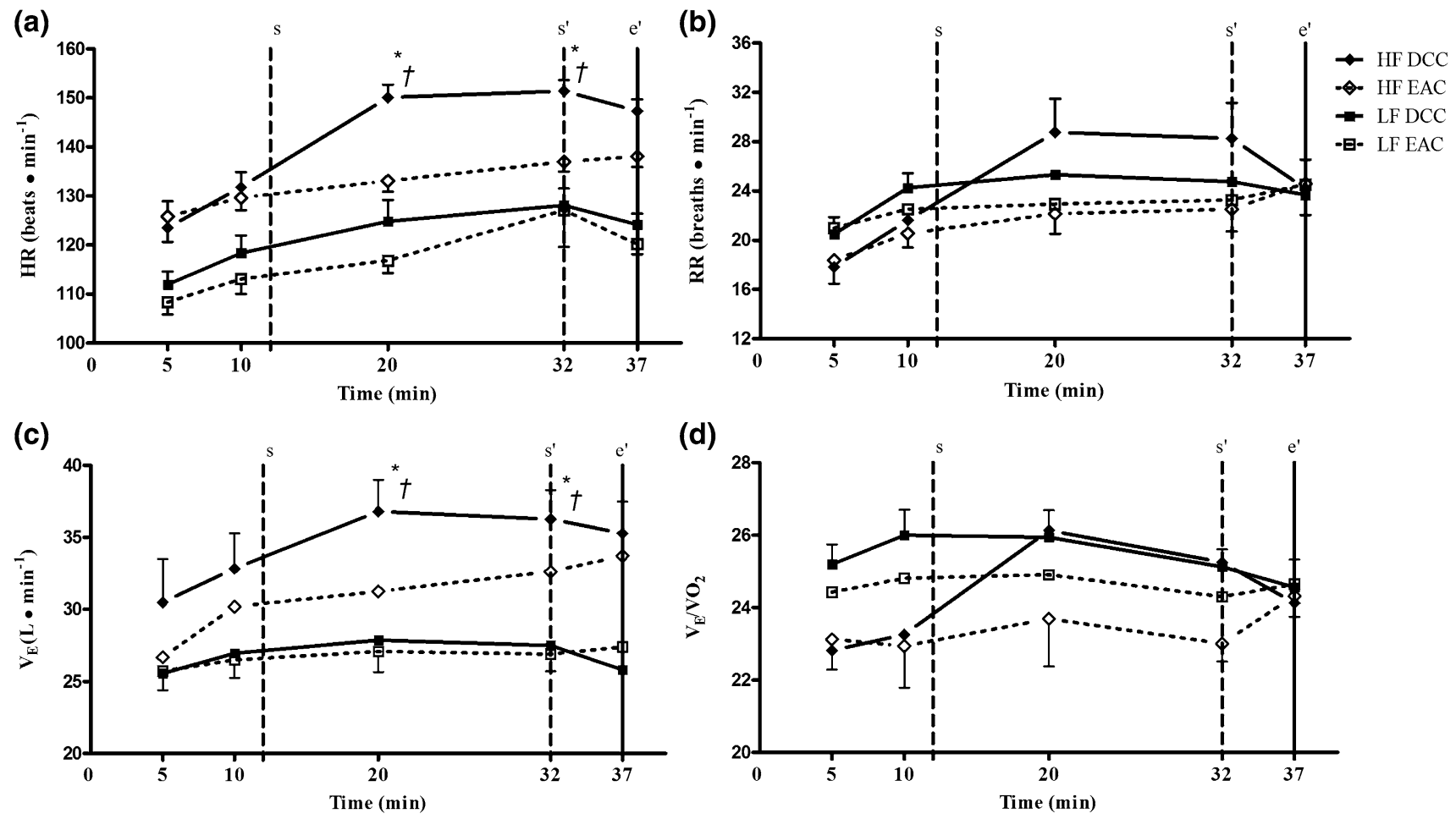

Fig. 4 Cardiorespiratory responses of HF and LF participants for a $\mathrm{HR}$, b RR, c $V_{\mathrm{E}}$, and d $V_{\mathrm{E}} / V \mathrm{O}_{2}$. Significant differences were seen in $\mathrm{HR}$ and RR between conditions and fitness levels at 20 and $32 \mathrm{~min}$ $\left({ }^{*} p<.05\right.$ between conditions; ${ }^{\dagger} p<.05$ between fitness levels). Points represent the $\mathrm{CR}$ values at specific time points during the protocol;

vertical lines depict standard errors of the means. The solid vertical lines extending from the ordinate represent the conclusion of the exercise $\left(e^{\prime}\right)$ component, while vertical dotted lines extending from the ordinate represent the start of the mental challenge $(s)$ and the end of the mental challenge $\left(s^{\prime}\right)$

Table 3 Cardiorespiratory responses between the aboveaverage (HF) and belowaverage (LF) fitness groups across time between the dual challenge (DCC) and exercisealone (EAC) conditions

\begin{tabular}{|c|c|c|c|c|c|}
\hline & $5 \min$ & $10 \mathrm{~min}$ & $20 \mathrm{~min}$ & $32 \mathrm{~min}$ & $37 \mathrm{~min}$ \\
\hline \multicolumn{6}{|c|}{ Heart rate (bpm) } \\
\hline HF DCC & $123.5 \pm 2.8^{\dagger}$ & $131.8 \pm 3.1^{\dagger}$ & $150.1 \pm 2.6^{\dagger}$ & $151.4 \pm 2.3^{\dagger}$ & $147.3 \pm 2.4^{\dagger}$ \\
\hline LF DCC & $111.9 \pm 2.6$ & $118.4 \pm 3.6$ & $124.8 \pm 4.4$ & $128.1 \pm 3.5$ & $124.1 \pm 2.3$ \\
\hline HF EAC & $125.8 \pm 3.1^{\dagger}$ & $129.6 \pm 2.8^{\dagger}$ & $133.0 \pm 2.1^{\dagger}$ & $137.0 \pm 2.0^{\dagger}$ & $138.1 \pm 2.2^{\dagger}$ \\
\hline LF EAC & $108.3 \pm 2.5$ & $113.1 \pm 3.1$ & $116.8 \pm 2.5$ & $127.1 \pm 7.4$ & $120.1 \pm 2.0$ \\
\hline \multicolumn{6}{|c|}{ Respiration rate (bpm) } \\
\hline HF DCC & $17.8 \pm 1.3$ & $21.6 \pm 1.7$ & $28.8 \pm 2.8^{\dagger}$ & $28.3 \pm 2.9^{\dagger}$ & $24.2 \pm 1.8$ \\
\hline LF DCC & $20.5 \pm 0.6$ & $24.3 \pm 1.2$ & $25.3 \pm 1.7$ & $24.8 \pm 1.6$ & $23.7 \pm 1.6$ \\
\hline HF EAC & $18.4 \pm 1.2$ & $20.5 \pm 1.1$ & $22.2 \pm 1.6$ & $22.5 \pm 1.8$ & $24.6 \pm 2.0$ \\
\hline LF EAC & $21.0 \pm 0.9$ & $22.5 \pm 1.1$ & $22.9 \pm 1.1$ & $23.4 \pm 0.9$ & $24.5 \pm 1.4$ \\
\hline \multicolumn{6}{|c|}{$V_{\mathrm{E}}\left(\mathrm{L}^{-1} \min \right)$} \\
\hline HF DCC & $30.49 \pm 3.00$ & $32.82 \pm 2.47$ & $36.80 \pm 2.17^{\dagger}$ & $36.26 \pm 2.03^{\dagger}$ & $35.28 \pm 2.20$ \\
\hline LF DCC & $25.56 \pm 0.92$ & $26.97 \pm 1.03$ & $27.86 \pm 0.96$ & $27.51 \pm 0.77$ & $25.80 \pm 1.32$ \\
\hline HF EAC & $26.68 \pm 1.87$ & $30.18 \pm 2.34$ & $31.25 \pm 2.42$ & $31.25 \pm 2.42$ & $32.63 \pm 2.00$ \\
\hline LF EAC & $25.70 \pm 1.31$ & $26.49 \pm 1.24$ & $27.07 \pm 1.42$ & $26.90 \pm 1.92$ & $27.38 \pm 1.24$ \\
\hline \multicolumn{6}{|c|}{$V \mathrm{E} / V \mathrm{O}_{2}\left(\mathrm{~L}^{-1} \mathrm{~min}\right)$} \\
\hline HF DCC & $22.81 \pm 1.28$ & $23.25 \pm 1.18$ & $26.13 \pm 1.10$ & $25.25 \pm 1.13$ & $24.13 \pm 0.75$ \\
\hline LF DCC & $25.19 \pm 0.56$ & $26.00 \pm 0.70$ & $25.94 \pm 0.75$ & $25.13 \pm 0.48$ & $24.56 \pm 0.76$ \\
\hline HF EAC & $23.13 \pm 0.84$ & $22.94 \pm 1.15$ & $23.69 \pm 1.31$ & $23.00 \pm 0.49$ & $24.32 \pm 0.57$ \\
\hline LF EAC & $24.42 \pm 0.89$ & $24.80 \pm 0.63$ & $24.90 \pm 0.67$ & $24.30 \pm 0.67$ & $24.64 \pm 0.56$ \\
\hline
\end{tabular}

Significant fitness differences between groups in the same condition 
Paired $t$ tests for EPI AUC (see Fig. 5b) revealed higher concentrations of EPI in the DCC compared to the EAC for all participants $(D C C=2739.58 \pm 460.54 \mathrm{p}$ $\mathrm{g} \mathrm{ml}^{-1} ; \mathrm{EAC}=1439.83 \pm 317.84 \mathrm{pg} \mathrm{ml}^{-1} ; t_{15}=2.25$, $p<0.05)$. HF participants demonstrated a greater EPI AUC in the DCC $\left(4034.23 \pm 542.37 \mathrm{pg} \mathrm{ml}^{-1}\right)$ compared to the EAC $\left(1387.34 \pm 619.17 \mathrm{pg} \mathrm{ml}^{-1} ; t_{7}=2.87\right.$, $p<.05$ ), whereas there were no differences between conditions for LF participants (see Fig. 5d). Analyses of NE AUC (see Fig. 5f) revealed higher relative concentrations of NE in the DCC compared to the EAC for all participants $\left(\mathrm{DCC}=14,296.11 \pm 1962.33 \mathrm{pg} \mathrm{ml}^{-1}\right.$; EAC $=95$ $\left.37.18 \pm 1281.37 \mathrm{pg} \mathrm{ml}^{-1} ; t_{15}=2.30, p<.05\right)$ with HF participants demonstrating a greater NE AUC in the DCC $\left(18,248.15 \pm 2352.23 \mathrm{pg} \mathrm{ml}^{-1}\right)$ compared to the EAC $\left(8740.76 \pm 2322.33 \mathrm{pg} \mathrm{ml}^{-1} ; t_{7}=3.50, p<.05\right)$, while there were no differences between conditions for LF participants (see Fig. 5h).

\section{Discussion}

This study examined the effects of a combination of acute mental challenges and physical stress on CR and catecholamine (EPI and NE) responses between LF and HF individuals. Self-report measures regarding perceptions of overall workload (NTLX) demonstrated that participants perceived greater anxiety and overall effort during the DCC compared to the EAC, despite an equivalent physiological workload $\left(V \mathrm{O}_{2}\right.$ and RER) between the two conditions for both fitness groups. Thus, the differences seen between the two conditions and fitness groups in this study can be attributed to the mental challenge, and not the physiological workload. This is the first study to demonstrate that cardiorespiratory fitness does impact the effect of concurrent stressors on CR and catecholamine responses.

Participants in this study had exacerbated $\mathrm{CR}$ responses (HR, RR, $V_{\mathrm{E}}, V_{\mathrm{E}} / V \mathrm{O}_{2}$ ) in the DCC compared to the EAC, with $\mathrm{HF}$ participants responding with greater absolute increases in $\mathrm{HR}, \mathrm{RR}, V_{\mathrm{E}}$, and $V_{\mathrm{E}} / V \mathrm{O}_{2}$ compared to the $\mathrm{LF}$ participants in the DCC. Further, HF participants also had a greater relative increase in HR compared to LF participants at the midpoint $(20 \mathrm{~min})$ and the conclusion $(32 \mathrm{~min})$ of the DCC. Additionally, HF participants also had a more immediate reduction in absolute HR post-mental challenge compared to LF participants. Overall, there were greater EPI and NE responses in the DCC, with HF individuals having more exacerbated EPI AUC and NE AUC responses in the DCC compared to the EAC. In contrast, LF individuals did not demonstrate significant EPI AUC or NE AUC differences between conditions.

These findings do not fully support the research hypothesis suggesting that LF participants would respond to the
DCC in a less metabolically efficient manner, with greater $\mathrm{CR}$ and catecholamine responses to the DCC. However, while it was found that HF participants did have higher CR, EPI, and NE responses to the DCC, it was also demonstrated that HF participants also had a more rapid recovery post-mental challenge for CR measures, and that the reduction in $\mathrm{NE}$ responses during the recovery period approached significance.

The exacerbated increases in $\mathrm{CR}$ responses to mental challenge during exercise in the DCC, compared to the EAC, observed in this experiment affirm the results of previous investigations (Acevedo et al. 2006; Roth et al. 1990; Rousselle et al. 1995; Szabo et al. 1994; Webb et al. 2008, 2010) in regard to a dual challenge situation. Further, the elevations in EPI and NE levels are also consistent with previous research that has demonstrated similar findings to a concomitant stress situation (Huang et al. 2010a, b, c; Webb et al. 2008, 2011b).

Included in this study was examination of the relative and absolute CR responses in LF and HF individuals. Previous researchers have suggested that elevations in CR measures are likely the result of the increased SA activation following the EPI and NE release from the SA axis, in response to challenging conditions of stress (physical and/ or psychological) such as the DCC (Acevedo et al. 2006; Rimmele et al. 2007; Roth et al. 1990; Rousselle et al. 1995; Szabo et al. 1994; Webb et al. 2010). The results of this study support this suggestion, as it was seen that HF individuals did have greater absolute and relative CR responses, and these significant elevations coincided with greater catecholamine values.

In this study, both the HF and LF groups were cycling at the same relative intensity of exercise $\left(60 \%\right.$ of $\left.V \mathrm{O}_{2 \text { peak }}\right)$ for each of the two conditions, with similar NTLX scores recorded across both fitness levels. There was also similar physical workload between the two conditions within each group. The HF group demonstrated consistent and significantly increased CR variables above that of the LF group, with greater absolute $\mathrm{HR}, \mathrm{RR}$, and $V_{\mathrm{E}}$ responses. This particular result would seem to confound the previous literature in which HR is attenuated in HF individuals compared to their LF counterparts during exercise alone (Crews and Landers 1987).

Additionally, this finding is contradictory of a similar study by Acevedo et al. (2006). However, there are critical methodological difference between the Acevedo et al. study and the current investigation which limit the ability to directly compare the findings of these two studies. The Acevedo et al. (2006) study utilized a shorter exercise duration and dual-challenge protocol (30 $\mathrm{min}$ of exercise and $8 \mathrm{~min}$ of mental challenge) with only a $5 \mathrm{~min}$ period allowed for participants to achieve steady-state, a workload of $65 \% \mathrm{VO}_{2 \text { peak }}$, and also included a mix of both male and 


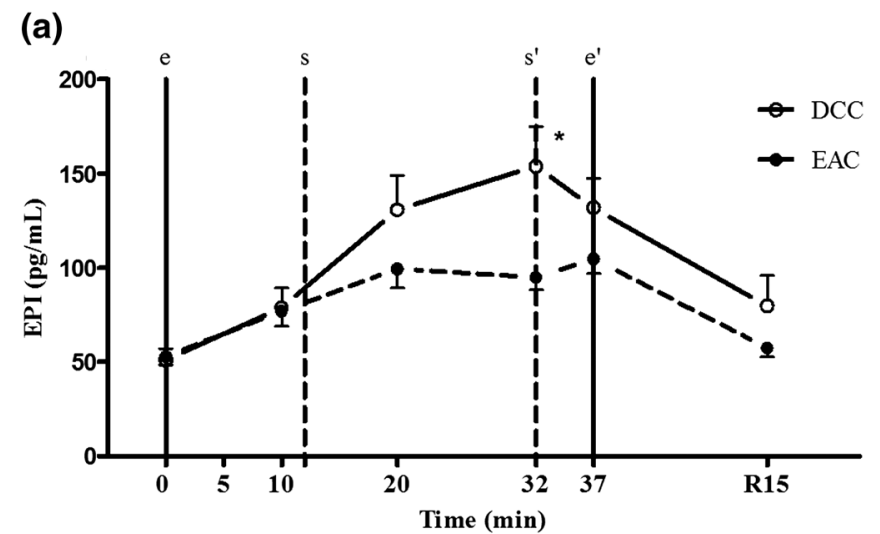

(b)
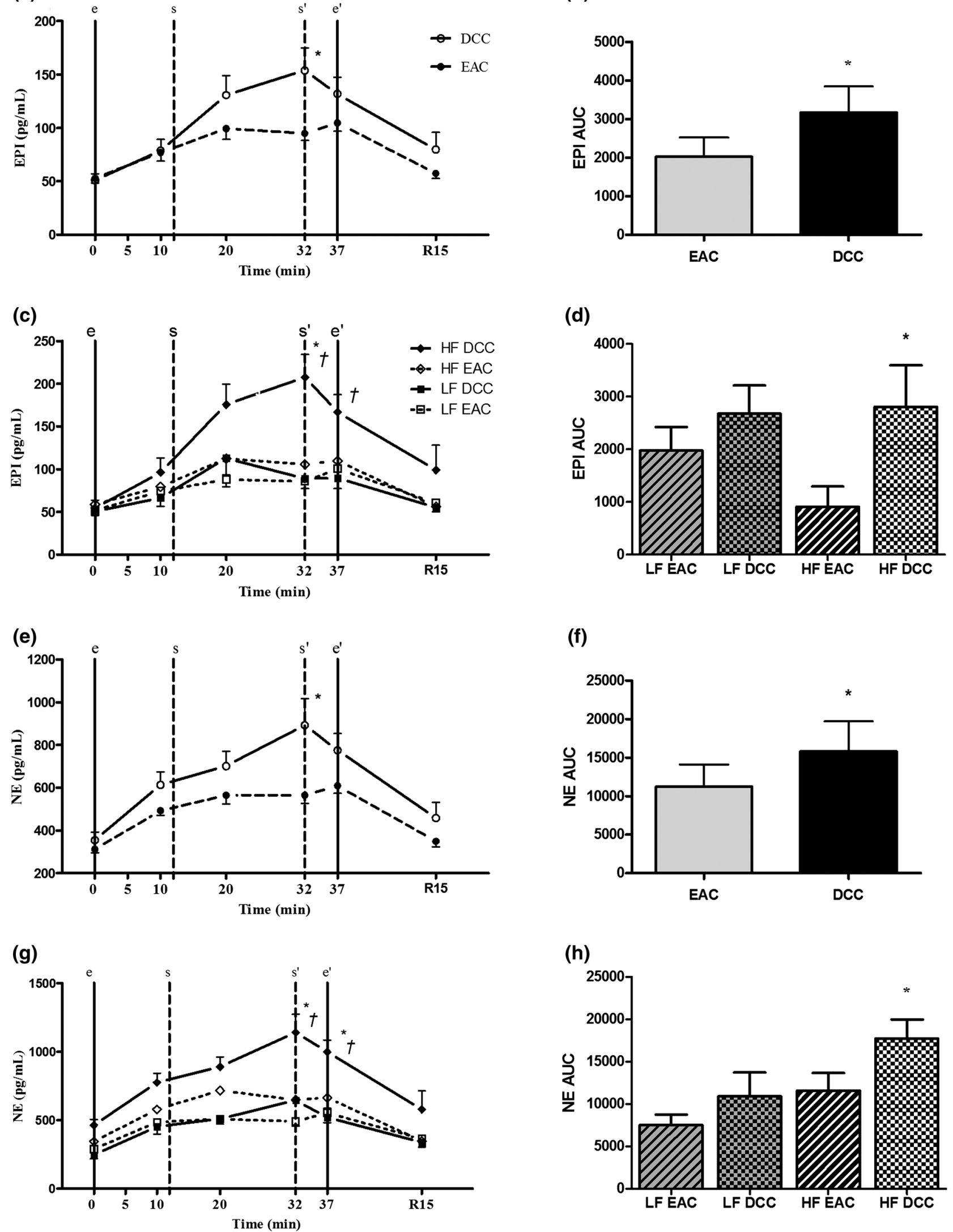
\Fig. 5 Catecholamine responses in the EAC and DCC between conditions [EPI $(\mathbf{a}, \mathbf{b})$ and NE $(\mathbf{c}, \mathbf{d})]$ and response differences between $\mathrm{HF}$ and LF participants in the DCC for EPI $(\mathbf{e}, \mathbf{f})$ and NE $(\mathbf{g}, \mathbf{h})$. Points represent the $\mathrm{CR}$ values at specific time points during the protocol; vertical lines depict standard errors of the means. The solid vertical lines extending from the ordinate represent the conclusion of the exercise $\left(e^{\prime}\right)$ component, while vertical dotted lines extending from the ordinate represent the start of the mental challenge $(s)$ and the end of the mental challenge $\left(s^{\prime}\right)$

female participants. As was also noted by Acevedo et al. (2006), the $65 \% V_{2} \mathrm{O}_{2 \max }$ intensity resulted in just under half the participants in that study working at an intensity above their ventilatory threshold (VT), while in this study only two participants (1 HF and $1 \mathrm{LF}$ ) were working at intensities above their estimated VT, and both those instances occurred in the EAC condition. The differences between the previous study and the current investigation were purposefully instituted in the current study to avoid issues outlined by the authors in the previous study.

The exacerbated CR responses of both fitness groups to the DCC appears to be uneconomical and unnecessary in meeting the physiological demands of the exercise, and the exacerbated responses would be the result of the added stress of the mental challenges. The effect was more pronounced in HF participants during the DCC, which suggests that cardiovascular fitness level may provide mechanistically different responses to concurrent challenges.

The concept of cardiovascular reactivity has been studied extensively, with conflicting results when considering CR fitness. Some studies support the notion of physiological hyper-reactivity to mental stress beyond an exercise stress response, and that fitness level attenuates HR and possibly other CR responses while participating in dual-stress conditions (Crews and Landers 1987; Delistraty et al. 1991, 1992; Rousselle et al. 1995; Szabo et al. 1994). The link between high fitness level and enhanced parasympathetic activity has also been suggested as a contributor to fitness differences in CR measures (Acevedo et al. 2006; Hamer and Steptoe 2007) and that increases in CR responses are due to decreases in vagal tone attributed to the parasympathetic nervous system (Hatfield et al. 1998; Smeets 2010; Spalding et al. 2000) or an increase in afferent sympathetic neuromuscular activation (Kaufman and Hayes 2002; Smith et al. 2006). However, a review by Jackson and Dishman (2006) suggests the reverse for mental stress alone, that those with high fitness level have increased reactivity to stressors, albeit with faster recovery times.

The findings of this study seem to lend greater credence to the suggestions of Jackson and Dishman (2006), as HF participants demonstrated greater HR, EPI, and NE responses compared to $\mathrm{LF}$, and that HF participants demonstrated a significant difference in HR values (faster HR recovery) as well as a trend toward quicker recovery for $\mathrm{NE}$ levels after the concurrent challenge. These findings suggest that fitness may be of benefit (and essential) to those engaged in situations where dual-stressors are common (emergency responders, military personnel, etc.), as greater activation of the SA axis may be essential to safety and survival.

While these findings suggest that concomitant stressors serve to cause a greater perturbation of the SA axis than a single stress alone, there are also general limitations to this study. First, the unique characteristics of the types of stressors utilized may not be ecologically valid. The physical stress of cycling in the laboratory setting may not be as intense as the physical challenges associated with occupations inherent with exposure to dual-stressors such as military personnel, law enforcement officers, firefighters, and other rescue workers. Furthermore, the psychological stress of the mental challenges may be perceived differently by each individual, according to familiarity or comfort level with mental arithmetic and the Stroop color word task and the anticipation of exercise or mental stress has also been shown to impact physiological responses (Acevedo et al. 1999; Baden et al. 2005; Webb et al. 2011a). Finally, the combination of physical and psychological stress experienced during the DCC is non-life threatening and may not concur with the reality of working in an occupation exposed to combined physical and psychological stress that could result in injury or death.

Overall, this study demonstrates that a dual-stress laboratory condition results in exacerbated CR and catecholamine responses which are affected by fitness level. It was expected that increases in these responses would be attenuated in individuals with higher fitness levels. This hypothesis was not supported. The catecholamine concentrations and resulting CR responses were higher in HF participants than in the LF participants.

Further investigation in this area is necessary to develop a greater understanding of how fitness impacts the SA axis in response stress, in particular to concurrent stressors. Focus on the mechanisms which may be responsible for the differences in responses between HF and LF individuals are crucial to determining if the greater absolute and relative CR changes are beneficial or detrimental to the performance and health of individuals with a greater cardiorespiratory fitness level. Finally, understanding the differences in SA axis responses in HF and LF individuals is important in planning for implementation strategies to prevent stress-induced dysfunction in individuals whose occupation includes psychological and physical stress.

Acknowledgements The authors wish to thank Supatchara Tangsilat and Kelly McCleod for their assistance in data collection with this project. 


\section{Compliance with ethical standards}

No external funding was received to conduct this study.

Conflict of interest The authors declare no conflicts of interest.Material has been reviewed by the Walter Reed Army Institute of Research. There is no objection to its presentation and/or publication. The opinions or assertions contained herein are the private views of the author, and are not to be construed as official, or as reflecting true views of the Department of the Army or the Department of Defense.

\section{References}

Acevedo EO, Dzewaltowski DA, Kubitz KA, Kraemer RR (1999) Effects of a proposed challenge on effort sense and cardiorespiratory responses during exercise. Med Sci Sports Exerc 31:1460-1465

Acevedo EO, Webb HE, Weldy ML, Fabianke EC, Orndorff GR, Starks MA (2006) Cardiorespiratory responses of hi fit and low fit subjects to mental challenge during exercise. Int J Sports Med 27:1013-1022

Baden DA, McLean TL, Tucker R, Noakes TD, St Clair Gibson A (2005) Effect of anticipation during unknown or unexpected exercise duration on rating of perceived exertion, affect, and physiological function. Br J Sports Med 39:742-746

Brotherhood JR, Budd GM, Hendrie AL, Jeffery SE, Beasley FA, Costin BP, Zhien W, Baker MM, Cheney NP, Dawson MP (1997) Project Aquarius. 3. Effects of work rate on the productivity, energy expenditure, and physiological responses of men building fireline with a rakehoe in dry eucalypt forest. Int J Wildl Fire 7:87-98

Claytor RP (1991) Stress reactivity: hemodynamic adjustments in trained and untrained humans. Med Sci Sports Exerc 23:873-881

Crews DJ, Landers DM (1987) A meta-analytic review of aerobic fitness and reactivity to psychosocial stressors. Med Sci Sports Exerc 19:S114-S120

Dayas CV, Buller KM, Crane JW, Xu Y, Day TA (2001) Stressor categorization: acute physical and psychological stressors elicit distinctive recruitment patterns in the amygdala and in medullary noradrenergic cell groups. Eur J Neurosci 14:1143-1152

de Geus EJ, van Doornen LJ (1993) The effects of fitness training on the physiological stress response. Work Stress 7:141-159

de Geus EJ, van Doornen LJ, Orlebeke JF (1993) Regular exercise and aerobic fitness in relation to psychological make-up and physiological stress reactivity. Psychosom Med 55:347-363

Delistraty DA, Greene WA, Carlberg KA, Raver KK (1991) Use of graded exercise to evaluate physiological hyperreactivity to mental stress. Med Sci Sports Exerc 23:476-481

Delistraty DA, Greene WA, Carlberg KA, Raver KK (1992) Cardiovascular reactivity in Type A and B males to mental arithmetic and aerobic exercise at an equivalent oxygen uptake. Psychophysiology 29:264-271

Dill DB, Costill DL (1974) Calculation of percentage changes in volumes of blood, plasma, and red cells in dehydration. J Appl Physiol 37:247-248

Hamer M, Steptoe A (2007) Association between physical fitness, parasympathetic control, and proinflammatory responses to mental stress. Psychosom Med 69:660-666

Hatfield BD, Spalding TW, Santa Maria DL, Porges SW, Potts JT, Byrne EA, Brody EB, Mahon AD (1998) Respiratory sinus arrhythmia during exercise in aerobically trained and untrained men. Med Sci Sports Exerc 30:206-214

Howley ET, Bassett DR Jr, Welch HG (1995) Criteria for maximal oxygen uptake: review and commentary. Med Sci Sports Exerc 27(9):1292-1301
Huang CJ, Webb HE, Evans RK, McCleod KA, Tangsilsat SE, Kamimori GH, Acevedo EO (2010a) Psychological stress during exercise: immunoendocrine and oxidative responses. Exp Biol Med (Maywood) 235:1498-1504

Huang CJ, Webb HE, Garten RS, Kamimori GH, Acevedo EO (2010b) Psychological stress during exercise: lymphocyte subset redistribution in firefighters. Physiol Behav 101:320-326

Huang CJ, Webb HE, Garten RS, Kamimori GH, Evans RK, Acevedo EO (2010c) Stress hormones and immunological responses to a dual challenge in professional firefighters. Int J Psychophysiol 75:312-318

Jackson EM, Dishman RK (2006) Cardiorespiratory fitness and laboratory stress: a meta-regression analysis. Psychophysiology 43:57-72

Kaufman MP, Hayes SG (2002) The exercise pressor reflex. Clin Auton Res 12:429-439

Mastorakos G, Pavlatou M, Diamanti-Kandarakis E, Chrousos GP (2005) Exercise and the stress system. Hormones (Athens) 4:73-89

Nicolaides NC, Kyratzi E, Lamprokostopoulou A, Chrousos GP, Charmandari E (2015) Stress, the stress system and the role of glucocorticoids. Neuroimmunomodulation 22:6-19

Pescatello LS (ed) (2013) ACSM's guidelines for exercise testing and prescription. Wolters Kluwer, Philadelphia

Rimmele U, Zellweger BC, Marti B, Seiler R, Mohiyeddini C, Ehlert U, Heinrichs M (2007) Trained men show lower cortisol, heart rate and psychological responses to psychosocial stress compared with untrained men. Psychoneuroendocrinology 32:627-635

Roth DL, Bachtler SD, Fillingim RB (1990) Acute emotional and cardiovascular effects of stressful mental work during aerobic exercise. Psychophysiology 27:694-701

Rousselle JG, Blascovich J, Kelsey RM (1995) Cardiorespiratory response under combined psychological and exercise stress. Int J Psychophysiol 20:49-58

Schuler JL, O'Brien WH (1997) Cardiovascular recovery from stress and hypertension risk factors: a meta-analytic review. Psychophysiology 34:649-659

Smeets T (2010) Autonomic and hypothalamic-pituitary-adrenal stress resilience: impact of cardiac vagal tone. Biol Psychol 84:290-295

Smith SA, Mitchell JH, Garry MG (2006) The mammalian exercise pressor reflex in health and disease. Exp Physiol 91:89-102

Sothmann MS, Hart BA, Horn TS (1991) Plasma catecholamine response to acute psychological stress in humans: relation to aerobic fitness and exercise training. Med Sci Sports Exerc 23:860-867

Sothmann MS, Buckworth J, Claytor RP, Cox RH, White-Welkley JE, Dishman RK (1996) Exercise training and the cross-stressor adaptation hypothesis. Exerc Sport Sci Rev 24:267-287

Spalding TW, Jeffers LS, Porges SW, Hatfield BD (2000) Vagal and cardiac reactivity to psychological stressors in trained and untrained men. Med Sci Sports Exerc 32:581-591

Szabo A, Péronnet F, Gauvin L, Furedy JJ (1994) Mental challenge elicits "additional" increases in heart rate during low and moderate intensity cycling. Int J Psychophysiol 17:197-204

Webb HE, Weldy ML, Fabianke-Kadue EC, Orndorff GR, Kamimori GH, Acevedo EO (2008) Psychological stress during exercise: cardiorespiratory and hormonal responses. Eur J Appl Physiol 104:973-981

Webb HE, McMinn DR, Garten RS, Beckman JL, Kamimori GH, Acevedo EO (2010) Cardiorespiratory responses of firefighters to a computerized fire strategies and tactics drill during physical activity. Appl Ergon 41:376-381

Webb HE, Fabianke-Kadue EC, Kraemer RR, Kamimori GH, Castracane VD, Acevedo EO (2011a) Stress reactivity to repeated 
low-level challenges: a pilot study. Appl Psychophysiol Biofeedback 36:243-250

Webb HE, Garten RS, McMinn DR, Beckman JL, Kamimori GH, Acevedo EO (2011b) Stress hormones and vascular function in firefighters during concurrent challenges. Biol Psychol $87: 152-160$
Webb HE, Rosalky DS, Tangsilsat SE, McLeod KA, Acevedo EO, Wax B (2013) Aerobic fitness affects cortisol responses to concurrent challenges. Med Sci Sports Exerc 45:379-386 